\title{
A systematic review of parenting interventions for child chronic health conditions
}

This is a post-peer-review, pre-copyedit version of an article published the Journal of Child Health Care. The final authenticated version is available online at: http://dx.doi.org/ 10.1177/1367493519882850

Manuscript Accepted 22 September 2019

Amy E. Mitchell*, BSc, BNursing, GradCert, PhD

Alina Morawska, BA, BSc(Hons), MPH, PhD

Mandy Mihelic, BPsyc(Hons), PhD

Parenting and Family Support Centre, School of Psychology, The University of Queensland

Running head: Parenting interventions for child health

\section{Funding:}

This work was supported by the Australian Research Council (DP140100781).

\section{Acknowledgements:}

Nil.

\section{Conflict of Interest Statement:}

The Parenting and Family Support Centre is partly funded by royalties stemming from published resources of the Triple P - Positive Parenting Program, which is developed and owned by The University of Queensland (UQ). Royalties are also distributed to the Faculty of Health and Behavioural Sciences at UQ and contributory authors of published Triple P resources. Triple P International (TPI) Pty Ltd is a private company licensed by Uniquest Pty Ltd on behalf of UQ, to publish and disseminate Triple $\mathrm{P}$ worldwide. The authors of this report have no share or ownership of TPI. Dr Morawska receives royalties from TPI. TPI had no involvement in the study design, collection, analysis or interpretation of data, or writing of this report. Dr Mitchell and Dr Mihelic are employees at UQ.

*Corresponding author: Amy Mitchell, Parenting and Family Support Centre, School of Psychology, The University of Queensland, St Lucia, 4072, Australia. Ph: +61 733461202. Fax: +61 73365 6724. Email: a.mitchell5@uq.edu.au 


\begin{abstract}
This systematic review summarises the parenting intervention literature for parents of children with chronic health conditions and evaluates intervention effects on parenting (parenting skills, parenting efficacy) and child (behaviour, illness severity/control, quality of life) outcomes. Systematic searches using seven electronic databases (including CINHAL, MEDLINE, PsycINFO) were used to identify relevant papers published in English between 1997 and 2017, and reference lists were searched for additional relevant articles. Ten papers reporting on eight separate studies met inclusion criteria: three studies evaluated stand-alone parenting interventions, while the remaining five studies included parenting components in broader interventions that also targeted medically-oriented aspects of illness management. Results suggest that parenting interventions may lead to improved parent self-efficacy, parenting behaviour, illness severity/control, child quality of life, and child behaviour; however, intervention effects were mixed and confined to parent-report outcome measures. A paucity of studies using rigorous randomised controlled trial study designs limits the conclusions that can be drawn regarding intervention efficacy. Achieving adequate enrolment and retention of families in parenting intervention trials appears to be problematic within these clinical groups. Larger samples and more diverse clinical populations will support the reliability of future evaluations of parenting interventions in this context and improve generalisability of results.
\end{abstract}

Key words: child health, child, chronic disease, parenting, systematic review 
Chronic childhood health conditions (e.g. asthma, eczema, diabetes) are common, increasing in prevalence, and impact on the child and family across multiple domains of functioning (Halterman et al., 2004; Moore et al., 2006). They contribute to elevated parental and family stress, irrespective of illness severity or duration (Cousino and Hazen, 2013), and greater parenting stress is associated with poorer parent and child psychological adjustment (Helgeson et al., 2012; Verkleij et al., 2015). Importantly, children with chronic health conditions are more likely to experience emotional and behavioral problems (Hysing et al., 2007; 2009), including both internalizing (LeBovidge et al., 2003; Vila et al., 2000) and externalizing problems (Borge et al., 2004), as well as social difficulties (Meijer et al., 2000). These can intensify parenting challenges and make condition management more difficult. Most childhood chronic health conditions require some form of prescribed management (e.g., symptom monitoring, medication, lifestyle interventions, physical therapies); however, approximately half of children do not adhere to prescribed treatment (Morton et al., 2014). Sub-optimal adherence is the major cause of treatment failure for many conditions (Bass et al., 2015), and results in poor disease control (Bender and Zhang, 2008) and increased risk of hospital admission (Rohan et al., 2010). Responsibility for children's illness management and treatment adherence ultimately rests with parents. Parents report that children's resistance to taking medication and other treatment is a major obstacle to adherence (Burgess et al., 2008; Santer et al., 2013) and children also recognise that simply not wanting to take their medication is a key barrier to adherence (Penza-Clyve et al., 2004). Compounding this problem, parents of children with chronic health conditions may lack the confidence and effective parenting skills to manage difficult child behaviour (Chiang et al., 2003; Mitchell et al., 2015). For example, parents can be reluctant to discipline their child (Holmbeck et al., 2002), tend to be more inconsistent in their discipline (Walker et al., 1995; Wilson et al., 1993), may have different expectations for their child's behaviour (Walker et al., 1995), and 
can be more hostile in their communication with their child (Murphy et al., 2016).

Parenting plays a central role in children's health outcomes (Wood et al., 2008) and parenting and family-level characteristics (e.g. parenting difficulties, parental mental health, family conflict) may contribute to disease onset and course (Mrazek et al., 1999; Rohan et al., 2014; Tibosch et al., 2011). Conversely, positive parenting, characterised by warm, responsive, and consistent parenting behaviour, is associated with better illness management (Davis et al., 2001), illness control and regimen adherence, better child adjustment (Jaser and Grey, 2010; Sullivan-Bolyai et al., 2003), and greater levels of health-related behaviours (Park and Walton-Moss, 2012). In contrast, lower parental self-efficacy for managing the child's condition (Streisand et al., 2005) and use of less effective parenting strategies (e.g. over- or under-involvement, overprotection or neglect, rigid expectations or lack of routine) (Gustafsson et al., 2002; Wade et al., 2000) are associated with poorer health and more child emotional and behavioural problems.

Parenting interventions have been extensively evaluated, and demonstrate positive effects on parental knowledge and skill, parent stress, parenting practices, and children's emotional and behavioural outcomes (Barlow et al., 2014; Barlow and Coren, 2018; Kaminski and Claussen, 2017). More recently, parenting programs have been pinpointed as an important component of paediatric chronic illness management (Morawska et al., 2015). However, existing approaches still largely focus on a medical education model to improve adherence, even though evidence suggests that the effects of such interventions are limited (Dean et al., 2010; Kahana et al., 2008; Pai and McGrady, 2014) and short-term (Kahana et al., 2008). While evidence-based medical interventions exist for many chronic health conditions, treatment is not likely to be effective if children do not follow their management plan. Given that around half of children do not adhere to their treatment, current medical approaches have failed in addressing the problem of adherence. In addition, they represent a missed 
opportunity to prevent and treat psychosocial problems which are increasingly shown to affect illness onset and severity.

Within the emerging literature there is growing recognition of the importance of synthesis research, which seeks to systematically integrate results from individual studies to examine the effects of parenting and family interventions on child and family outcomes, including parent mental health and child health symptoms, and provide a more thorough description of the current state of research (e.g. Eccleston et al., 2012; Law et al., 2014). In their systematic reviews and meta-analyses of psychological interventions (cognitive behavioural therapy, family therapy, problem solving therapy, and multisystemic/systems therapy) for parents of children and adolescents with chronic illness, Eccleston et al. (2012) and Law et al. (2014) each found that problem solving therapy demonstrated a positive effect on parents' mental health and behaviour. Law et al. (2014) further identified an effect of pooled psychological therapies on parent behaviour. There were no effects for other intervention types on parent, child, or family outcomes (Eccleston et al., 2012; Law et al., 2014). While these metaanalyses support the assertion that parent- and family-based psychological interventions can impact on outcomes in the childhood chronic illness context, the reviews took a broad approach by examining a wide range of interventions that targeted parents of both children and adolescents, with considerable variation in the degree of parent involvement in interventions. Except for systematic reviews of parenting interventions for a single diagnostic group (e.g. diabetes; Lohan et al., 2015) no systematic review has specifically examined the effect of parenting interventions on child and parent outcomes in the childhood chronic illness context.

The purpose of the current systematic review is to summarise the findings of studies that examine parenting interventions for families of young children (birth to 10 years) with a chronic health condition, and evaluate intervention effects on specific parenting (skills, 
efficacy) and child (behaviour, illness severity/control, quality of life) outcomes important to improved illness management for children and families. We use a narrative synthesis framework to summarise the findings of primary studies, and the Grading of Recommendations Assessment, Development, and Evaluation (GRADE) criteria (Schunemann et al., 2013) to provide an indication of quality of existing evidence.

We have taken a cross-condition approach because empirical evidence suggests that the type of condition does not predict child and family adjustment; rather, factors such as family environment, illness severity and chronicity play more important roles (e.g., Bennett, 1994; Stein and Jessop, 1989; Svavarsdottir and Arlygsdattir, 2006). Models of service provision that focus on common illness factors (e.g., stress management, managing child resistance to treatment, establishing routines) have been suggested as an effective means to make services available to a wider range of children (Morison et al., 2003). We have previously argued that in order for interventions to be viable and sustainable they need to be effective for families of children with a variety of chronic illnesses, rather than focusing on a single diagnostic category (Morawska et al., 2015). The birth to 10-year age range was chosen in recognition that developmental tasks particular to childhood and adolescence are very different, and many parent-focused child health interventions encompass a broad child age range with upper limits of around 10-14 years. Searches for relevant articles were limited to the past 20 years to ensure that retrieved articles would be relevant to the contemporary paediatric health care context.

\section{Search strategy}

\section{Method}

Systematic searches for articles published between 1997 and December 2017, in the English language, were conducted using seven electronic databases: CINHAL, MEDLINE, PsycINFO, PubMed, Scopus, The Cochrane Library and Web of Science. Search terms were adapted to meet specific requirements of each database, and are presented in Table 1. Cross- 
referencing and forward searches were completed on identified full-text articles.

\section{Inclusion criteria}

Studies needed to meet the following inclusion / exclusion criteria:

1. Type of studies. Studies could be randomised controlled trials or uncontrolled studies, and use any comparison group (e.g., wait-list, care as usual, education).

2. Types of participants. Parents of children aged from birth to 10 years old (or mean age below 10 years, if the study included older children), with a chronic health condition, including: asthma, hay fever, allergies, chronic sinusitis, eczema, atopic dermatitis, diabetes, epilepsy, migraine, cystic fibrosis, arthritis, anaemia, muscular dystrophy, otitis media, bronchitis, phenylketonuria, or any other health problems of the renal, cardiovascular, metabolic, or endocrine systems. Studies primarily targeting cancer, obesity, or behavioural and emotional problems were excluded.

3. Type of intervention. The study had to evaluate a parenting intervention that aimed to improve parenting practices such as skills, competencies, styles or behaviour or parenting confidence/efficacy. Parenting practices could include general parenting or specific practices relevant to the health condition or management thereof. For interventions that included parenting as a component of a larger intervention package, a defined parenting aspect that meets the above criteria had to be specified. Interventions such as family interventions (e.g., family therapy), those that focus on parental adjustment (e.g., cognitive behaviour therapy for depression), or skills training related to specific management of the illness such as educating parents about the illness and teaching specific treatments (e.g., how to administer insulin injections) were excluded. The intervention could be of any theoretical orientation, such as psycho-educational, behavioural, counselling, health promotion, or self-management, and could be of any delivery format or dosage.

4. Types of outcome measures. Studies had to assess at least one parenting outcome, 
including parenting skills or parenting efficacy; or one or more child outcomes, including child behaviour, illness severity (or control), or health-related quality of life.

\section{Data extraction and quality review}

The full search yield was reviewed for inclusion in the review based on title, abstract and full-text (by research assistant CM-P), and reviews of eligible full-text papers (by AEM and MM) confirmed adherence to inclusion criteria. Data extracted from each paper included study and participant characteristics, study design, intervention characteristics, relevant outcome measures, and results. The Cochrane Risk of Bias tool (Higgins et al., 2011) was used to evaluate study quality in terms of random sequence generation, allocation concealment, blinding of participants and personnel, blinding of outcome assessment, incomplete outcome data, selective reporting and bias not otherwise specified (such as contamination), selective reporting of subgroups, sample size limitations, missing information, and generalisability of study findings. Each criterion was categorized as having low, unclear, or high risk of bias.

\section{Results}

The search yielded 10 eligible papers, reporting on eight separate studies, for inclusion in this review (see Figure 1). All reported on evaluations of an intervention using a randomised controlled trial (RCT) design and were published between 1999 and 2017. Throughout this paper, the term "significance" refers to statistical (not clinical) significance.

\section{Participant and Study Characteristics}

Table 2 summarises participant and study characteristics. Studies were conducted with a total of 347 families from five different countries (United Kingdom, Australia, United States, Venezuela, and Germany). Sample sizes ranged from 7 to 107 families. Three studies included both mothers and fathers, although one reported only mother outcomes due to insufficient data from fathers (McCusker et al., 2012) and another reported outcomes for 
mothers and fathers separately (Morawska et al., 2016; 2017a; 2017b). Two studies included only mothers, and three did not report parent gender. Child age ranged from 2 to 14 years, with mean ages of 3.7 to 9.2 years. One study did not report the mean age of the children (Pérez et al., 1999). Interventions targeted outcomes for children with type 1 diabetes $(n=2)$, asthma ( $n=2)$, asthma and/or eczema $(n=1)$, cystic fibrosis $(n=2)$ and congenital heart disease $(n=1)$.

\section{Types of Interventions}

Table 2 provides a detailed overview of the components of each intervention program. All interventions included a specified parenting component, which aimed to improve parenting skills or confidence and taught parenting strategies. Three studies tested what were predominantly stand-alone parenting interventions, with a lesser component providing information on the specific illness. The other five studies tested interventions which incorporated a parenting component into a broader intervention which focused predominantly on the medical aspects of the illness (Pérez et al., 1999), a specific aspect of illness management (Stark et al., 2003; 2016), or strategies to support parent coping and adjustment (McCusker et al., 2012; Saßmann et al., 2012).

Parental engagement in family-focused interventions can be described in terms of focus, structure, and level of engagement (Knafl et al., 2017). The focus of all eight studies was to improve parent role performance (e.g., parenting behaviours, parent-child interactions) as well as condition management capacity (e.g., condition-specific knowledge, management skills, self-efficacy). Most also explicitly aimed to improve family functioning (e.g., roles, relationships, processes) (Clarke et al., 2014; McCusker et al., 2012; Morawska et al., 2016; Morawska et al., 2017a; Morawska et al., 2017b; Saßmann et al., 2012; Westrupp et al., 2015). In terms of structure, only one intervention (Stark et al., 2003) included a childdirected component, which was delivered separately to the parent-focused intervention. 
Seven studies described active parental engagement/participation (e.g., role-playing, problem-solving); only one study (Pérez et al., 1999) described relatively passive parental engagement (i.e., information transfer).

Overall, the eight studies reported on the outcomes of five different interventions: the Triple $\mathrm{P}$ - Positive Parenting Program ( $\mathrm{n}=3$ studies, $\mathrm{n}=5$ papers; Clarke et al., 2014; Morawska et al., 2016; 2017a; 2017b; Westrupp et al., 2015); the DELFIN Parenting Program ( $n=1$; Saßmann et al., 2012); BeInCharge.org and its un-named precursor intervention ( $\mathrm{n}=2$; Stark et al., 2003; 2016); the Congenital Heart Disease Intervention Programme (CHIP)-School (McCusker et al., 2012); and another unnamed program (Pérez et al., 1999). The Triple P interventions, although delivered in different formats and with varying lengths, were all stand-alone parenting interventions aimed at enhancing parenting knowledge, skills and confidence; promoting more positive and nurturing environments; and teaching strategies to manage children's problematic behaviours. The DELFIN Parenting program by Saßmann et al. (2012) focused on behavioural principles and parenting strategies to manage child behaviour. BeInCharge.org and its precursor program by Stark and colleagues $(2003 ; 2016)$ combined behavioural intervention and nutritional education, teaching parents effective child behaviour management strategies as a means to improve condition management. The CHIP-School program by McCusker and colleagues (2012) aimed to bolster general and condition-specific parenting skills as part of a broader program also targeting child adjustment, maternal worry, unhelpful beliefs and roadblocks to effective parenting. The final intervention (Pérez et al., 1999) focused mainly on the medical aspects of illness management but also addressed psychological aspects including managing children's emotions and behaviour.

Interventions were delivered in a group format $(n=5)$, online $(n=2)$ or individually $(n=1)$, typically by psychologists $(n=3)$, nurses $(n=1)$, or a multidisciplinary team (e.g. 
psychologist/dietician, $n=1$; psychologist/nurse/cardiologist, $n=1$ ). The medical management component of one intervention was delivered by an allergy specialist, however it is unclear who delivered the psychological content of this intervention (Pérez et al., 1999). For the two interventions delivered online there was no facilitator (Clarke et al., 2014; Stark et al., 2016).

The interventions varied in length from 2 to 10 weeks, with at least two sessions and up to 10 sessions, except for one of the online interventions which did not have specified sessions (Clarke et al., 2014). Sessions ran for 45 to 90 minutes each, although one program also incorporated a 5-hour group workshop (McCusker et al., 2012). Of the eight studies, two interventions were delivered (online) in the family home (Clarke et al., 2014; Stark et al., 2016), one at a university psychology clinic (Morawska et al., 2016; 2017a; 2017b), one at a children's hospital (Westrupp et al., 2015), and one at a regional healthcare centre (McCusker et al., 2012). Three papers did not report the location of the intervention sessions.

\section{Risk of Bias Assessment and Quality of Evidence}

Table 3 summarises the risk of bias for each of the eight studies. Most presented with either low or unclear risk of bias across all domains; thus, all were included in this review. Due to the nature of the interventions, blinding of participants or personnel was not possible in any of the interventions. Blinding of the outcome assessment was generally not reported or possible in the self-report measures, which were the predominant form of outcome measurement. Table 4 summarises results from evaluation of study outcomes using GRADE methodology. As per the GRADE approach, the RCTs started as high-quality evidence, and were rated down primarily due to small sample sizes and heterogeneity in study findings.

\section{Outcomes Assessed}

The studies all included at least one of the outcomes pre-specified for inclusion in this review: parenting outcomes, such as skills, efficacy and confidence; and child outcomes, including child behaviour, illness severity/control or health, or health-related quality of life. 
All studies used standardised parent-report measures, and two studies accessed medical records or hospital-based pathology services to obtain biomedical data (Saßmann et al., 2012; Westrupp et al., 2015). Table 2 summarises the measures used in each study.

\section{Effects of the Intervention on Outcomes}

Due to the small number of studies eligible for inclusion in this review and heterogeneity of study outcome variables, a meta-analysis could not be conducted. Moreover, one study did not present any results in terms of intervention efficacy: Clarke et al. (2014) lacked postassessment data due to all but one participant dropping out of the intervention and postassessment. Thus, a narrative synthesis of findings from the remaining seven studies is presented. A summary of findings, including appraisals of available evidence using the GRADE criteria, is provided in Table 4.

Parent outcomes. Parent self-efficacy and parenting behaviour were assessed in four studies. Morawska et al. (2016; 2017b) reported effects on parents' self-efficacy for managing their child's condition and/or illness-related behaviours, finding significant intervention effects for parents' self-efficacy with eczema management for both mothers and fathers, but not with asthma management. Parents' self-efficacy improved for dealing with eczema-related problem behaviours for mothers but not fathers; again, there was no effect on the comparable asthma measure. Westrupp et al. (2015) assessed effects on general parenting self-efficacy, finding no intervention effect for the overall sample but a significant improvement for the subsample of families with pre-existing internalising/externalising child behaviour problems.

In terms of parenting behaviours, there were significant intervention effects for parentreport measures but no effects reported on observational measures of parenting behaviour (Morawska et al., 2017a; Saßmann et al., 2012; Stark et al., 2003; Westrupp et al., 2015). Significant improvements in ineffective parenting, measured using the Parenting Scale 
(Arnold et al., 1993), were found for all studies assessing this outcome (Morawska et al., 2017a; Saßmann et al., 2012; Westrupp et al., 2015). The Parenting Scale assesses use of ineffective parenting strategies across three subscales: overreactivity (authoritarian discipline, displays of anger), laxness (permissive discipline), and verbosity (overly long reprimands, reliance on talking). All three studies reported consistent improvements in overreactivity, some with additional effects on total score ( $n=2$ studies), verbosity ( $n=2$ studies), and laxness ( $n=1$ studies). Although Saßmann et al. (2012) reported similar improvements for their control group only the intervention group improvements were maintained at follow-up. Westrupp et al. (2015) found a stronger effect for families with pre-existing problems, with significant effects on more subscales. In contrast, Saßmann et al. (2012) found no effect on the Questions to Education Behaviour scale which assesses positive helping and reinforcing parenting behaviour and was used alongside the Parenting Scale. For observational measures of parenting behaviour no significant intervention effects were found (Morawska et al., 2017a; Stark et al., 2003).

Child Outcomes. Child outcomes included either child behaviour or health-related outcomes, including illness or symptom severity or control and health-related quality of life.

Health outcomes. Seven of the eight studies reported on illness severity or control, most reporting positive intervention effects on child health measures. Two studies (Morawska et al., 2016; Pérez et al., 1999) reported significant improvements in asthma and eczema symptoms for the intervention groups at post-intervention and follow-up. Two studies (Stark et al., 2003; 2016) reported significantly greater increases in body mass and weight-forheight percentiles for children with cystic fibrosis in the behavioural intervention (compared to nutritional education only) groups at post-intervention and follow-up. McCusker et al. (2012) reported fewer parent-reported sick days for children with congenital heart disease in the intervention group at follow-up. Only glycaemic control for children with diabetes, 
assessed in two studies (Saßmann et al., 2012; Westrupp et al., 2015), was not found to improve for the intervention groups in either study; however, the Saßmann et al. (2012) control group demonstrated a small but statistically significant worsening of glycaemic control by 3 months post-intervention.

Child health-related quality of life was assessed in two papers from one study (Morawska et al., 2016; 2017b) which found a significant improvement in the intervention group for child quality of life when reported by fathers, but not when reported by mothers with both groups significantly improving on this outcome over time.

Child behaviour. Child behaviour was assessed in five of the eight studies (McCusker et al., 2012; Morawska et al., 2016; 2017a; 2017b; Saßmann et al., 2012; Stark et al., 2003; Westrupp et al., 2015) with some evidence of intervention effectiveness on these outcomes. Morawska et al. (2016; 2017a; 2017b) found significantly greater improvements in the intensity and number of general child behaviour problems and the extent of eczema-related behaviour problems from pre- to post-assessment for the intervention group compared to usual care (Morawska et al., 2016; 2017a). However, there was no change in mother-reported asthma-related behaviour problems, father-reported asthma- or eczema-related behaviour problems, children's emotional adjustment, or measures of observed child behaviour.

Westrupp et al. (2015) found a significant effect on child behaviour for the subsample of families who had pre-existing internalising/externalising child behaviour problems, but not when all participants were analysed together. Saßmann et al. (2012) found no intervention effect on child behaviour, although the intervention group decreased significantly in the number of children within the cut-off for clinical problems. Likewise, Stark et al. (2003) and McCusker et al. (2012) found no difference between intervention and control groups on measures of children's mealtime or general behaviour, respectively.

\section{Discussion}


An emerging body of literature describes the development and evaluation of parenting interventions for parents of children with chronic health conditions (Lohan et al., 2016; Mackey et al., 2016). Parenting intervention research in the childhood chronic illness context summarized herein provides some evidence for the efficacy of parenting interventions in improving a range of parent and child variables that are important to short- and long-term child health outcomes.

Only 10 papers reporting on eight studies met inclusion criteria. All were RCTs conducted in outpatient settings and evaluated intervention effects on one or more parenting (e.g., parenting skills, parenting efficacy) or child (behaviour, illness severity/control, HRQoL) outcomes. Despite variation in target populations and treatment components, each intervention included a defined parenting intervention component that aimed to improve parenting practices, skills, competencies, self-efficacy, parenting styles or behaviours, either from a general parenting perspective or specifically in relation to illness management.

Of the eight RCTs included in this review, only the three Triple P interventions were considered predominantly stand-alone parenting interventions. Clarke et al.'s (2014) UKbased trial of Online Group Seminar Series Triple P for parents of children with asthma was an online group program of 8 weeks' duration. Although asthma symptoms, child behaviour, parenting behaviour and parenting self-efficacy were identified as planned outcomes, loss of all study participants early in the trial precluded any evaluation of intervention efficacy. Comparisons of outcomes from the remaining two Triple $\mathrm{P}$ intervention trials, Westrupp et al.’s (2015) 10-session individually-delivered Triple P intervention and Morawska et al.'s (2016; 2017a; 2017b) 2-session Positive Parenting for Healthy Living (Triple P) group program, both trialed in Australia, reveal inconsistent results. The 10-session program for parents of children with type 1 diabetes resulted in a significant improvement in ineffective parenting (overreactivity, verbosity) for the intervention group compared to standard care at 
3-months post-intervention; however, there was no effect on child behaviour, metabolic control, laxness or overall ineffective parenting behaviour, or parenting efficacy; and no intervention effects sustained to 12-months post-intervention (Westrupp et al., 2015). Secondary analyses did, however, detect intervention effects across several measures for families where children had pre-existing behaviour difficulties, suggesting a moderating effect of child behaviour difficulties on intervention effects. In contrast, the 2-session discussion group program for parents of children with asthma and/or eczema (Morawska et al., 2016; 2017a; 2017b) reported positive effects on ineffective parenting (total, overreactivity), general child behaviour problems, parents' self-efficacy with eczema management, eczema-related child behaviour difficulties and parents' self-efficacy for managing the behaviours, children's HRQoL, parent-reported eczema symptom severity, and parent-reported number of asthma episodes per week. However, despite significant effects on general measures of parenting and child behaviour for the full sample, illness-specific intervention effects seemed largely confined to eczema-specific outcomes; there were no effects for other parent-report asthma measures (parent self-efficacy, child behaviour); some intervention effects were found for mothers but not fathers, and vice versa; and, consistent with Stark et al. (2003), effects were limited to parent-reported (rather than directly observed) parent and child behaviour.

Results from the other five studies, in which parenting intervention components were included in broader interventions that also addressed medical management skills and knowledge, suggest an overall picture of intervention effects on illness management/control outcomes but little effect on parent or child behaviour. Perez et al.'s (1999) trial of a 2session group program for parents of children with asthma demonstrated positive intervention effects for asthma morbidity and was the only parenting-intervention-as-component study to also find an effect on child behaviour. The two studies testing the combined behavioural and 
nutritional intervention (BeInCharge) for parents of children with cystic fibrosis (Stark et al., 2003 ; 2016) found significant intervention effects on children's weight gain, an important indicator of cystic fibrosis control, but no effect on observed parent or child behaviour. McCusker et al.'s (2012) CHIP-School program found fewer mother-reported child sick days for the intervention group compared to control, but again, no effect on measures of child behaviour. Finally, Saßmann et al.’s (2012) 6-session DELFIN Program for parents of children with type 1 diabetes demonstrated little effect on parenting or child behaviour or metabolic control, although metabolic control did deteriorate in the control group at 3-months post-intervention compared to the intervention group, which remained unchanged.

In summary, intervention effects arising from RCTs of parenting programs included in this review are mixed, and comparison between studies is difficult due to the heterogeneity of intervention content and structure, delivery modality, clinical targets, extent of child coparticipation, and duration of follow-up. Particularly given the limited number of studies available for inclusion in this review, it must be concluded that research evaluating the efficacy of parenting intervention for parents of children with chronic health conditions is still in its infancy, and there is, as yet, insufficient evidence to draw conclusions about the efficacy of parenting interventions for these clinical groups. The pattern of results does support our cross-condition approach, however, with little indication of parenting interventions being more/less effective for specific child health conditions.

Papers included in this review confirm that engagement and retention of parents in parenting intervention programs remains a problem. Sample sizes were small, most with $N<40$, and attrition from several of the smallest studies was substantial, and sufficient to preclude any outcome analyses in one case (Clarke et al., 2014). Although parents of children with chronic health conditions have been considered a "hard-to-reach" population in parenting research contexts (Clarke et al., 2014), for work in this area to progress we must 
examine why this continues to be so. Firstly, do families in fact want or need parenting support? As described earlier, numerous studies point to relationships between ineffective parenting behaviours, child behaviour difficulties and less positive child health outcomes; however, it may be that families do not perceive a problem, and view their child's behaviour as either normative or simply to be expected given their child's physical condition and limitations. Mismatch between clinician and parent perspectives when estimating psychosocial difficulties in families of children with chronic health conditions are not uncommon (e.g., Boogerd et al., 2015), with parents tending to report fewer problems compared to health care professionals.

For parents, the pull between investing time and energy in medical management and disease education as opposed to psychosocial interventions must also be anticipated. While the feasibility and value of incorporating parenting support into multidisciplinary chronic illness management has been demonstrated (LeBovidge et al., 2007), the issue for parents may be one of prioritisation, where finite energy and resources are allocated to that which is considered most likely to benefit their child. Observations from our own clinical work with families suggest that parents remain largely unaware of the link between child behaviour and parenting difficulties and child health outcomes. Approaches to persuading parents of the value and benefit of parenting interventions in the chronic illness context need to be considered and tested.

Continued efforts are also needed to better understand how to tailor intervention delivery to encourage and facilitate the involvement of parents with extraordinary caregiving responsibilities but who may still be keen to connect with other parents. The balance between the convenience of an online intervention must be weighed against the advantages of interpersonal connectivity of a group program, for example. Thus, future experimentation with mode of delivery will be important to optimising feasibility and uptake of parenting 
interventions in these populations.

It is difficult to ascertain the effectiveness of parenting interventions in a chronic illness context unless a coordinated effort is made to systematically examine which approaches work best for which clinical groups, and, indeed, for which individuals. Despite strong evidence supporting the links between parenting and child health outcomes, the limited number of studies examining parenting interventions in this context suggests worryingly slow progression of research in this area. Lack of consistency between studies in terms of intervention outcomes makes synthesis difficult. Three studies did not assess parenting style/behaviour as an outcome even though parenting was a proximal intervention target, thus limiting inferences that can be made about mechanisms of action. Appropriate infrastructure is needed to support clinical trials of psychosocial interventions in the child health arena, commensurate with the potential impact such approaches will have on health care efficacy and child health outcomes. A commitment from clinicians, parents, and funders is needed to enable researchers to rigorously test, refine, and implement parenting intervention approaches in this context.

Results of this review must be interpreted with caution. The conclusions that can be drawn from any systematic review are limited by the quality and reliability of the included studies. Firstly, only a small number of studies met our inclusion criteria, most with a small $(N<40)$ sample size. Secondly, only English language papers were included, risking exclusion of relevant non-English papers. Finally, meta-analysis was not possible due to the multicomponent nature of the interventions and heterogeneity of outcomes assessed. Nevertheless, the included studies provide some evidence that parenting intervention can contribute to improved outcomes for children with chronic health conditions. Appropriate funding and support is needed to recruit and retain sufficiently large samples in robustly designed, adequately powered, and carefully reported trials to progress work in this field. 


\section{References}

Arnold DS, O'Leary SG, Wolff LS, et al. (1993) The Parenting Scale: A measure of dysfunctional parenting in discipline situations. Psychological Assessment 5: 137-144.

Barlow J and Coren E. (2018) The effectiveness of parenting programs: a review of Campbell reviews. Research on Social Work Practice 28: 99-102.

Barlow J, Smailagic N, Huband N, et al. (2014) Group-based parent training programmes for improving parental psychosocial health (Review). Cochrane Database of Systematic Reviews: Art. No.: CD002020.

Bass A, Anderson K and Feldman S. (2015) Interventions to increase treatment adherence in pediatric atopic dermatitis: A systematic review. Journal of Clinical Medicine 4: 231242.

Bender B and Zhang L. (2008) Negative affect, medication adherence, and asthma control in children. Journal of Allergy and Clinical Immunology 122: 490-495.

Bennett DS. (1994) Depression among children with chronic medical problems: A metaanalysis. Journal of Pediatric Psychology. Special Issue: Chronic illness 19: 149-169.

Boogerd EA, Damhuis AMA, van Alfen-van der Velden JAAEM, et al. (2015) Assessment of psychosocial problems in children with type 1 diabetes and their families: the added value of using standardised questionnaires in addition to clinical estimations of nurses and paediatricians. Journal of Clinical Nursing 24: 2143-2151.

Borge AIH, Wefring KW, Lie KK, et al. (2004) Chronic illness and aggressive behaviour: A population-based study of 4-year-olds. European Journal of Developmental Psychology 1: 19-29.

Burgess SW, Sly PD, Morawska A, et al. (2008) Assessing adherence and factors associated with adherence in young children with asthma. Respirology 13: 559-563. 
Chiang LC, Huang JL and Lu CM. (2003) Educational diagnosis of self-management behaviors of parents with asthmatic children by triangulation based on PRECEDEPROCEED model in Taiwan. Patient Education and Counseling 49: 19-25.

Clarke SA, Calam R, Morawska A, et al. (2014) Developing web-based Triple P 'Positive Parenting Programme' for families of children with asthma. Child: Care, Health and Development 40: 492-497.

Cousino MK and Hazen RA. (2013) Parenting stress among caregivers of children with chronic illness: A systematic review. Journal of Pediatric Psychology 38: 809-828.

Davis CL, Delamater AM, Shaw KH, et al. (2001) Brief report: Parenting styles, regimen adherence, and glycemic control in 4- to 10-year-old children with diabetes. Journal of Pediatric Psychology 26: 123-129.

Dean AJ, Walters J and Hall A. (2010) A systematic review of interventions to enhance medication adherence in children and adolescents with chronic illness. Archives of Disease in Childhood 95: 717-723.

Eccleston C, Palermo TM, Fisher E, et al. (2012) Psychological interventions for parents of children and adolescents with chronic illness. Cochrane Database of Systematic Reviews 15: CD009660.

Gustafsson P, Kjellman N-I and Bjorksten B. (2002) Family interaction and a supportive social network as salutogenic factors in childhood atopic illness. Pediatric Allergy and Immunology 13: 51-57.

Helgeson VS, Becker D, Escobar O, et al. (2012) Families with children with diabetes: Implications of parent stress for parent and child health. Journal of Pediatric Psychology 37: 467-478.

Higgins JPT, Altman DG, Gotzsche PC, et al. (2011) The Cochrane Collaboration's tool for assessing risk of bias in randomised trials. British Medical Journal 343: d5928. 
Holmbeck GN, Johnson SZ, Wills KE, et al. (2002) Observed and perceived parental overprotection in relation to psychosocial adjustment in preadolescents with a physical disability: The mediational role of behavioral autonomy. Journal of Consulting \& Clinical Psychology 70: 96-110.

Hysing M, Elgen I, Gillberg C, et al. (2007) Chronic physical illness and mental health in children. Results from a large-scale population study. Journal of Child Psychology and Psychiatry 48: 785-792.

Hysing M, Elgen I, Gillberg C, et al. (2009) Emotional and behavioural problems in subgroups of children with chronic illness: results from a large-scale population study. Child: Care, Health and Development 35: 527-533.

Jaser SS and Grey M. (2010) A pilot study of observed parenting and adjustment in adolescents with Type 1 diabetes and their mothers. Journal of Pediatric Psychology 35: 738-747.

Kahana S, Drotar D and Frazier T. (2008) Meta-analysis of psychological interventions to promote adherence to treatment in pediatric chronic health conditions. Journal of Pediatric Psychology 33: 590-611.

Kaminski JW and Claussen AH. (2017) Evidence base update for psychosocial treatments for disruptive behaviours in children. Journal of Clinical Child and Adolescent Psychology 46: 477-499.

Knafl KA, Havill NL, Leeman J, et al. (2017) The nature of family engagement in interventions for children with chronic conditions. Western Journal of Nursing Research 39: 690-723.

Law EF, Fisher E, Fales J, et al. (2014) Systematic review and meta-analysis of parent and family-based interventions for children and adolescents with chronic medical conditions. Journal of Pediatric Psychology 39: 866-886. 
LeBovidge JS, Kelley SD, Lauretti A, et al. (2007) Integrating medical and psychological health care for children with atopic dermatitis. Journal of Pediatric Psychology 32: 617-625.

LeBovidge JS, Lavigne JV, Donenberg GR, et al. (2003) Psychological adjustment of children and adolescents with chronic arthritis: A meta-analytic review. Journal of Pediatric Psychology 28: 29-39.

Lohan A, Mitchell A, Sofronoff K, et al. (2016) Positive Parenting for Healthy Living (Triple P) for parents of children with type 1 diabetes: protocol of a randomised controlled trial. BMC Pediatrics 16: 158.

Lohan A, Morawska A and Mitchell A. (2015) A systematic review of parenting interventions for parents of children with Type 1 diabetes. Child: Care, Health \& Development 41: 803-817.

Mackey ER, Herbert L, Monaghan M, et al. (2016) The feasibility of a pilot intervention for parents of young children newly diagnosed with type 1 diabetes. Clinical Practice in Pediatric Psychology 4: 35-50.

McCusker CG, Doherty NN, Molloy B, et al. (2012) A randomized controlled trial of interventions to promote adjustment in children with congenital heart disease entering school and their families. Journal of Pediatric Psychology 37: 1089-1103.

Meijer SA, Sinnema G, Bijstra JO, et al. (2000) Social functioning in children with a chronic illness. Journal of Child Psychology and Psychiatry 41: 309-317.

Mitchell A, Fraser J, Ramsbotham J, et al. (2015) Childhood atopic dermatitis: A crosssectional study of relationships between child and parent factors, atopic dermatitis management, and disease severity. International Journal of Nursing Studies 52: 216228. 
Morawska A, Calam R and Fraser J. (2015) Parenting interventions for childhood chronic illness: A review and recommendations for intervention design and delivery. Journal of Child Health Care 19: 5-17.

Morawska A, Mitchell A, Burgess S, et al. (2017a) Randomized controlled trial of Triple P for parents of children with asthma or eczema: Effects on parenting and child behavior. Journal of Consulting and Clinical Psychology 85: 283-296.

Morawska A, Mitchell AE, Burgess S, et al. (2016) Effects of Triple P parenting intervention on child health outcomes for childhood asthma and eczema: Randomised controlled trial. Behaviour Research and Therapy 83: 35-44.

Morawska A, Mitchell AE, Burgess S, et al. (2017b) Fathers' perceptions of change following parenting intervention: randomized controlled trial of Triple P for parents of children with asthma or eczema. Journal of Pediatric Psychology 42: 792-803.

Morison JE, Bromfield LM and Cameron HJ. (2003) A Therapeutic Model for Supporting Families of Children with a Chronic Illness or Disability. Child and Adolescent Mental Health 8: 125-130.

Morton RW, Everard ML and Elphick HE. (2014) Adherence in childhood asthma: the elephant in the room. Archives of Disease in Childhood 99: 949-953.

Mrazek D, Klinnert M, Mrazek P, et al. (1999) Prediction of early onset asthma in genetically at risk children. Pediatric Pulmonology 27: 85-94.

Murphy LK, Murray CB and Compas BE. (2016) Topical review: Integrating findings on direct observation of family communication in studies comparing pediatric chronic illness and typically developing samples. Journal of Pediatric Psychology 42: 85-94.

Pai ALH and McGrady M. (2014) Systematic review and meta-analysis of psychological interventions to promote treatment adherence in children, adolescents, and young adults with chronic illness. Journal of Pediatric Psychology 39: 918-931. 
Park H and Walton-Moss B. (2012) Parenting style, parenting stress, and children's healthrelated behaviors. Journal of Developmental and Behavioral Pediatrics 33: 495-503.

Penza-Clyve SM, Mansell C and McQuaid EL. (2004) Why don't children take their asthma medications? A qualitative analysis of children's perspectives on adherence. Journal of Asthma 41: 189-197.

Pérez MG, Feldman L and Caballero F. (1999) Effects of a self-management educational program for the control of childhood asthma. Patient Education and Counseling 36: $47-55$.

Rohan J, Drotar D, McNally K, et al. (2010) Adherence to pediatric asthma treatment in economically disadvantaged African-American children and adolescents: An application of growth curve analysis. Journal of Pediatric Psychology 35: 394-404.

Rohan JM, Rausch JR, Pendley JS, et al. (2014) Identification and prediction of group-based glycemic control trajectories during the transition to adolescence. Health Psychology 33: $1143-1152$.

Santer M, Burgess H, Yardley L, et al. (2013) Managing childhood eczema: qualitative study exploring carers' experiences of barriers and facilitators to treatment adherence. Journal of Advanced Nursing 69: 2493-2501.

Saßmann H, de Hair M, Danne T, et al. (2012) Reducing stress and supporting positive relations in families of young children with type 1 diabetes: A randomized controlled study for evaluating the effects of the DELFIN parenting program. BMC Pediatrics 12: $152-162$.

Schunemann H, Brozek J, Guyatt G, et al. (2013) GRADE handbook for grading quality of evidence and strength of recommendations. Updated October 2013. Available at: guidelinedevelopment.org/handbook. 
Stark LJ, Opipari-Arrigan L, Filigno SS, et al. (2016) Web-based intervention for nutritional management in cystic fibrosis: Development, usability, and pilot trial. Journal of Pediatric Psychology 41: 510-521.

Stark LJ, Opipari LC, Spieth LE, et al. (2003) Contribution of behavior therapy to dietary treatment in cystic fibrosis: A randomized controlled study with 2-year follow-up. Behavior Therapy 34: 237-258.

Stein REK and Jessop DJ. (1989) What diagnosis does not tell: The case for a noncategorical approach to chronic illness in childhood. Social Science and Medicine 29: 769-778.

Streisand R, Swift E, Wickmark T, et al. (2005) Pediatric parenting stress among parents of children with Type 1 Diabetes: The role of self efficacy, responsibility, and fear. Journal of Pediatric Psychology 30: 513-521.

Sullivan-Bolyai S, Knafl K, Deatrick J, et al. (2003) Maternal management behaviors for young children with Type 1 diabetes. American Journal of Maternal Child Nursing 28: $160-166$.

Svavarsdottir EK and Arlygsdattir B. (2006) Comparison of health-related quality of life among 10- to 12-year-old children with chronic illnesses and healthy children: The parents' perspective. The Journal of School Nursing 22: 178-185.

Tibosch MM, Verhaak CM and Merkus PJFM. (2011) Psychological characteristics associated with the onset and course of asthma in children and adolescents: A systematic review of longitudinal effects. Patient Education and Counseling 82: 1119.

Verkleij M, van de Griendt EJ, Colland V, et al. (2015) Parenting stress related to behavioral problems and disease severity in children with problematic severe asthma. Journal of Clinical Psychology in Medical Settings 22: 179-193. 
Vila G, Nollet-Clemencon C, de Blic J, et al. (2000) Prevalence of DSM IV anxiety and affective disorders in a pediatric population of asthmatic children and adolescents. Journal of Affective Disorders 58: 223-231.

Wade SL, Holden G, Lynn H, et al. (2000) Cognitive-behavioral predictors of asthma morbidity in inner-city children. Journal of Developmental \& Behavioral Pediatrics 21: $340-346$.

Walker LS, Garber J and Van Slyke DA. (1995) Do parents excuse the misbehavior of children with physical or emotional symptoms? An investigation of the pediatric sick role. Journal of Pediatric Psychology 20: 329-345.

Westrupp E, Northam E, Lee K, et al. (2015) Reducing and preventing internalizing and externalizing behavior problems in children with type 1 diabetes: A randomized controlled trial of the Triple P-Positive Parenting Program. Pediatric Diabetes 16: $554-563$.

Wood BL, Lim J, Miller BF, et al. (2008) Testing the biobehavioral family model in pediatric asthma: Pathways of effect. Family Process 47: 21-40. 
Table 1. Search terms for CINHAL, MEDLINE, PsycINFO, PubMed, Scopus, The Cochrane Library and Web of Science

[1] child* OR neonat* OR infant* OR baby OR babies OR toddler* OR pre-school* OR preschool* OR school-age* OR youth* OR pre-adolescent* OR paediatric* OR pediatric* AND

[2] parent OR parenting OR mother OR father OR maternal OR paternal OR family OR families

AND

[3] intervent* OR program* OR support* OR training* OR practice* OR skill* OR competenc* OR behavior* OR style* OR efficacy* OR self-efficacy OR confidence* OR strateg*

AND

[4] asthma OR "hay fever" OR "allergic rhinitis" OR allergy OR "chronic sinusitis" OR eczema OR "atopic dermatitis" OR diabetes OR epilepsy OR migraine OR "cystic fibrosis" OR kidney OR renal OR cardiac OR heart OR cardiovascular OR arthritis OR "otitis media" OR bronchitis OR phenylketonuria OR metabolic OR thyroid* OR muscular dystrophy OR anaemia OR sickle cell 

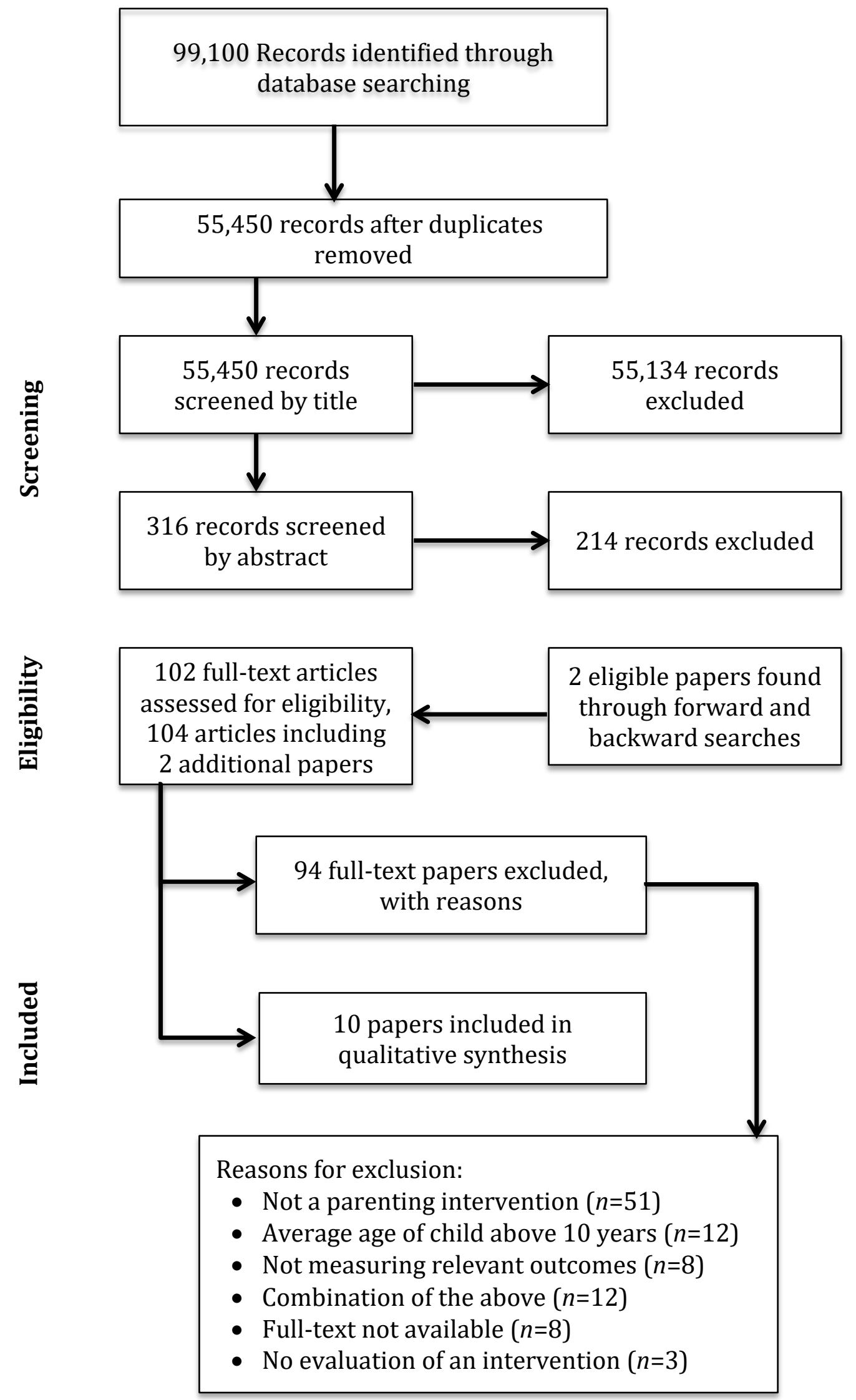

Figure 1. Preferred Reporting Items for Systematic Reviews and Meta-Analyses (PRISMA) flow diagram of search results 
Table 2. Study Characteristics of included papers

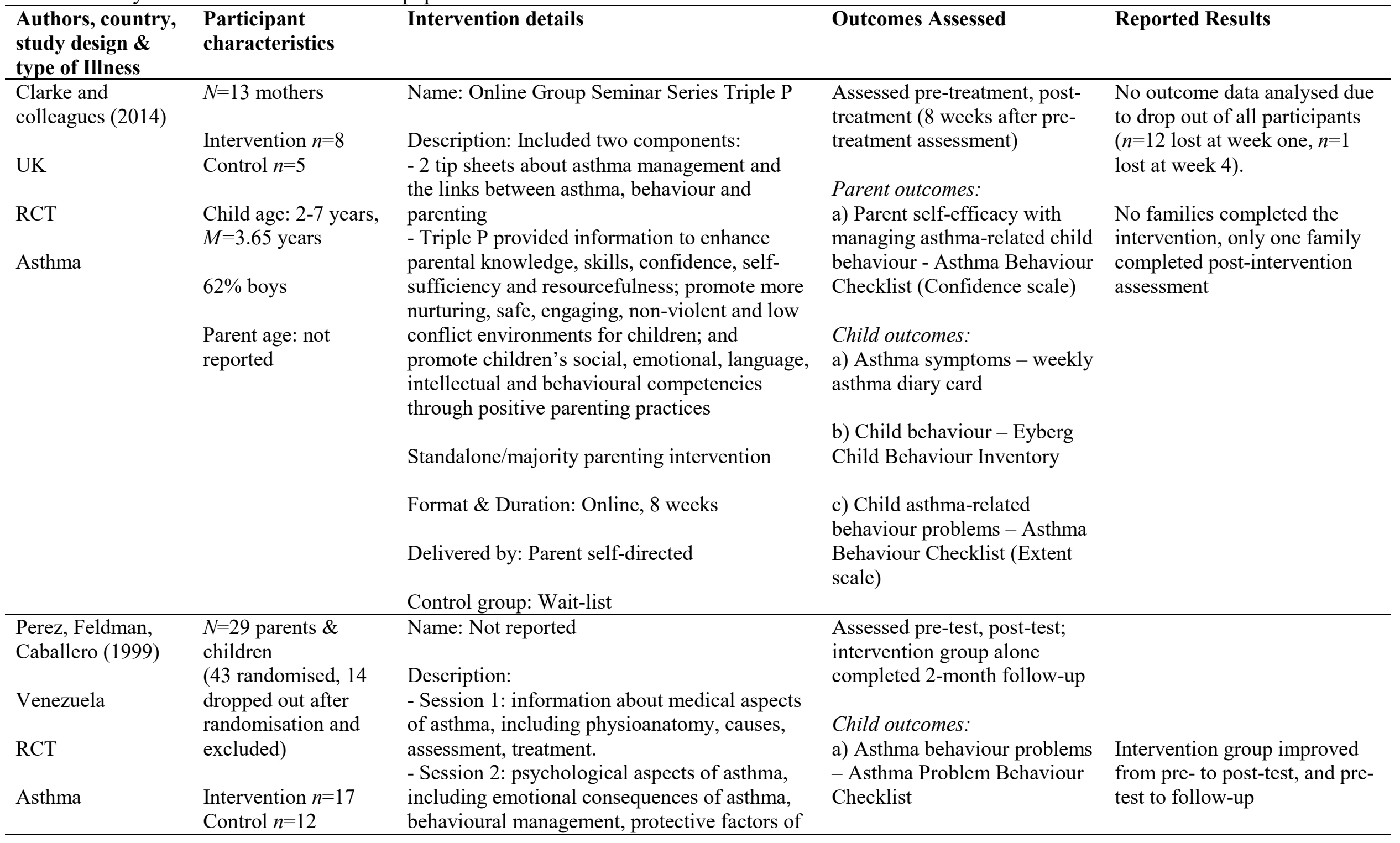




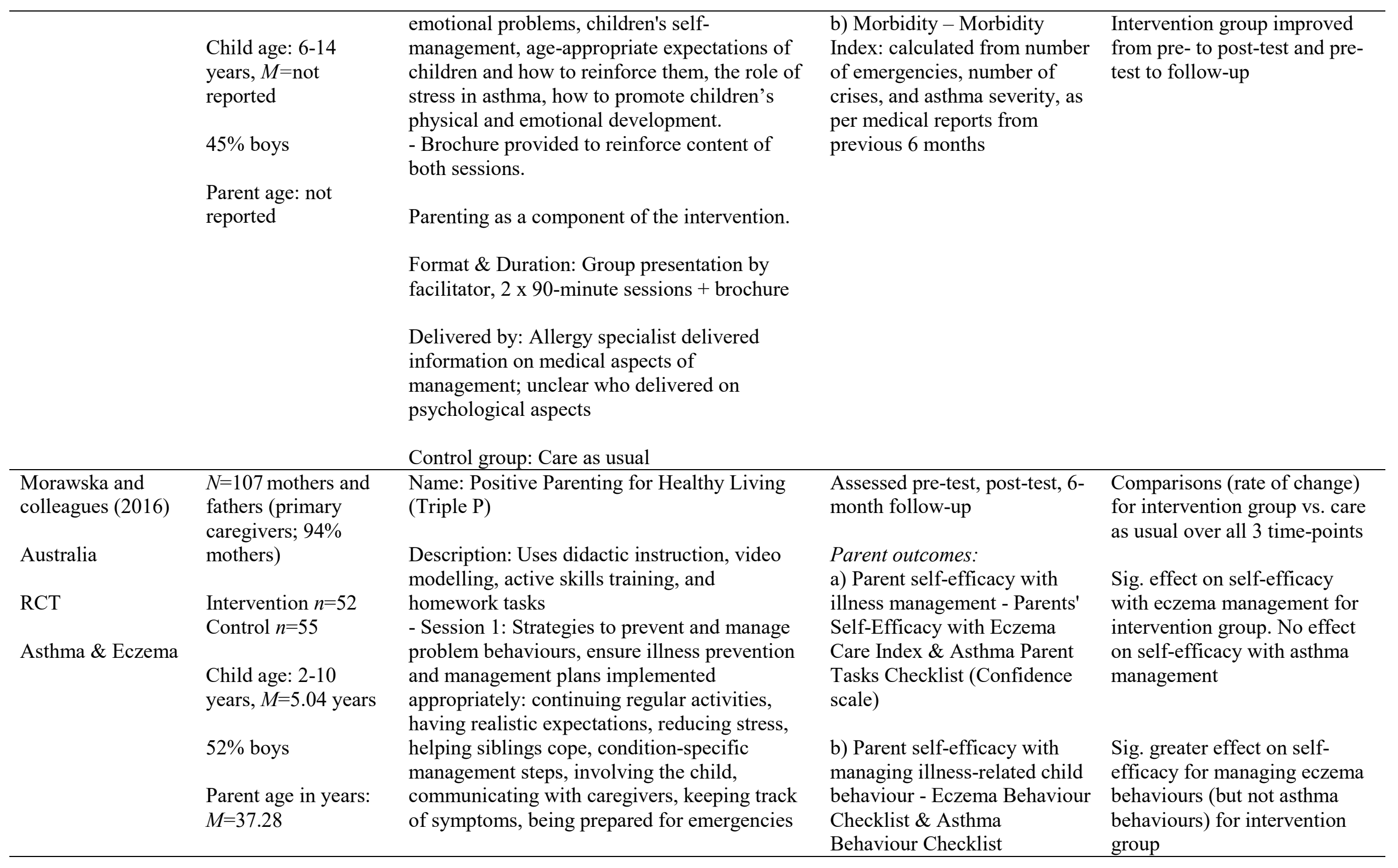




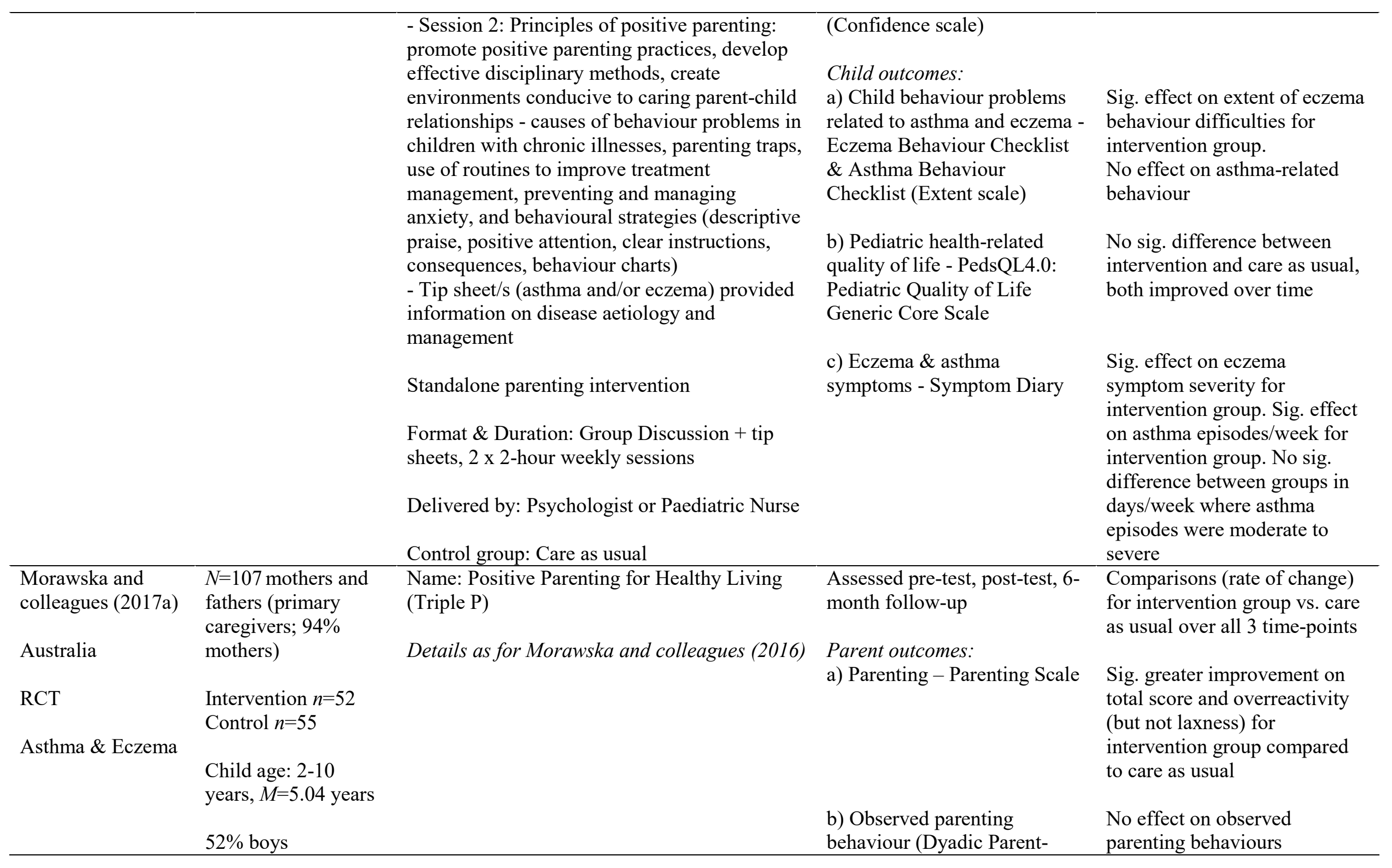




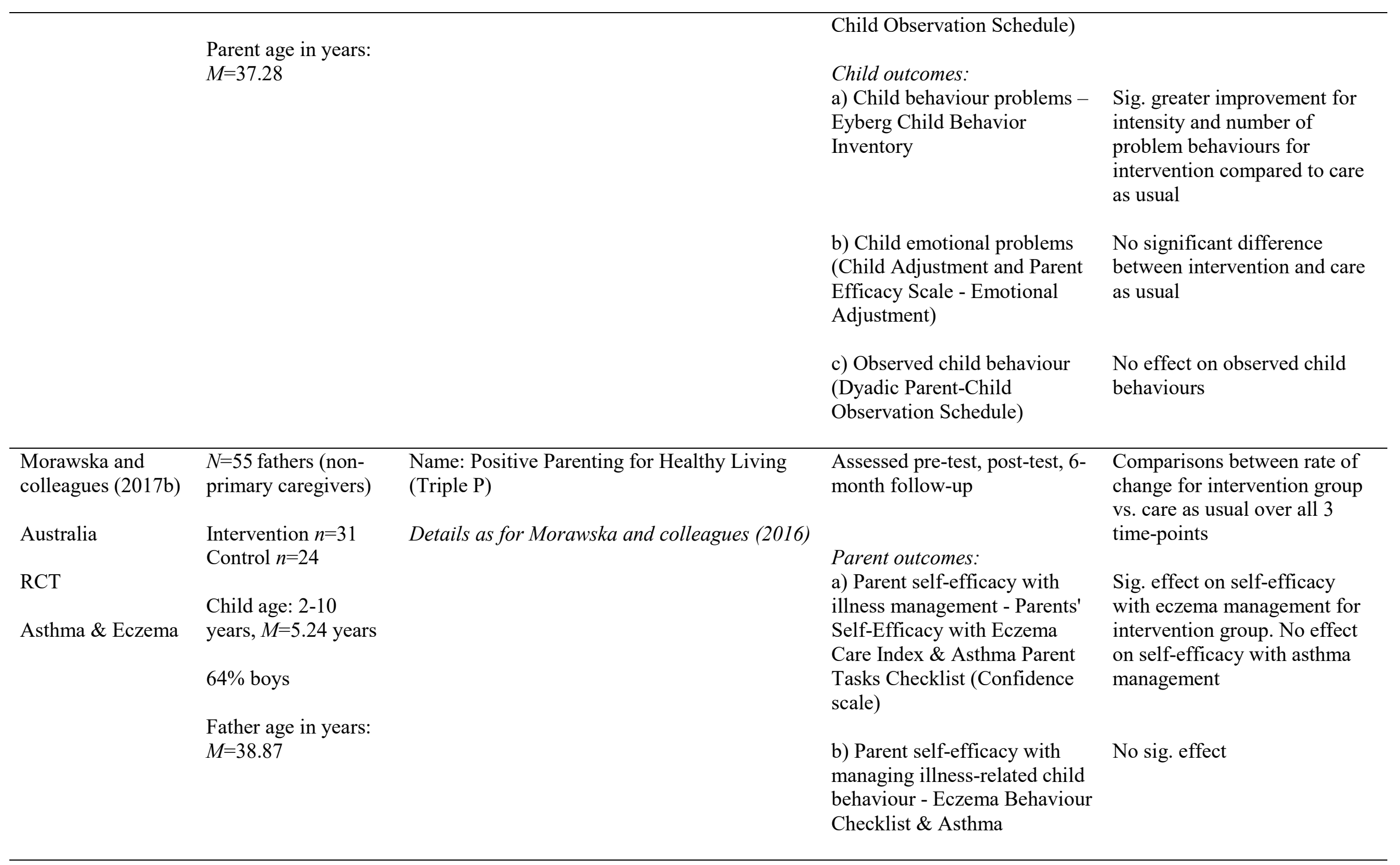




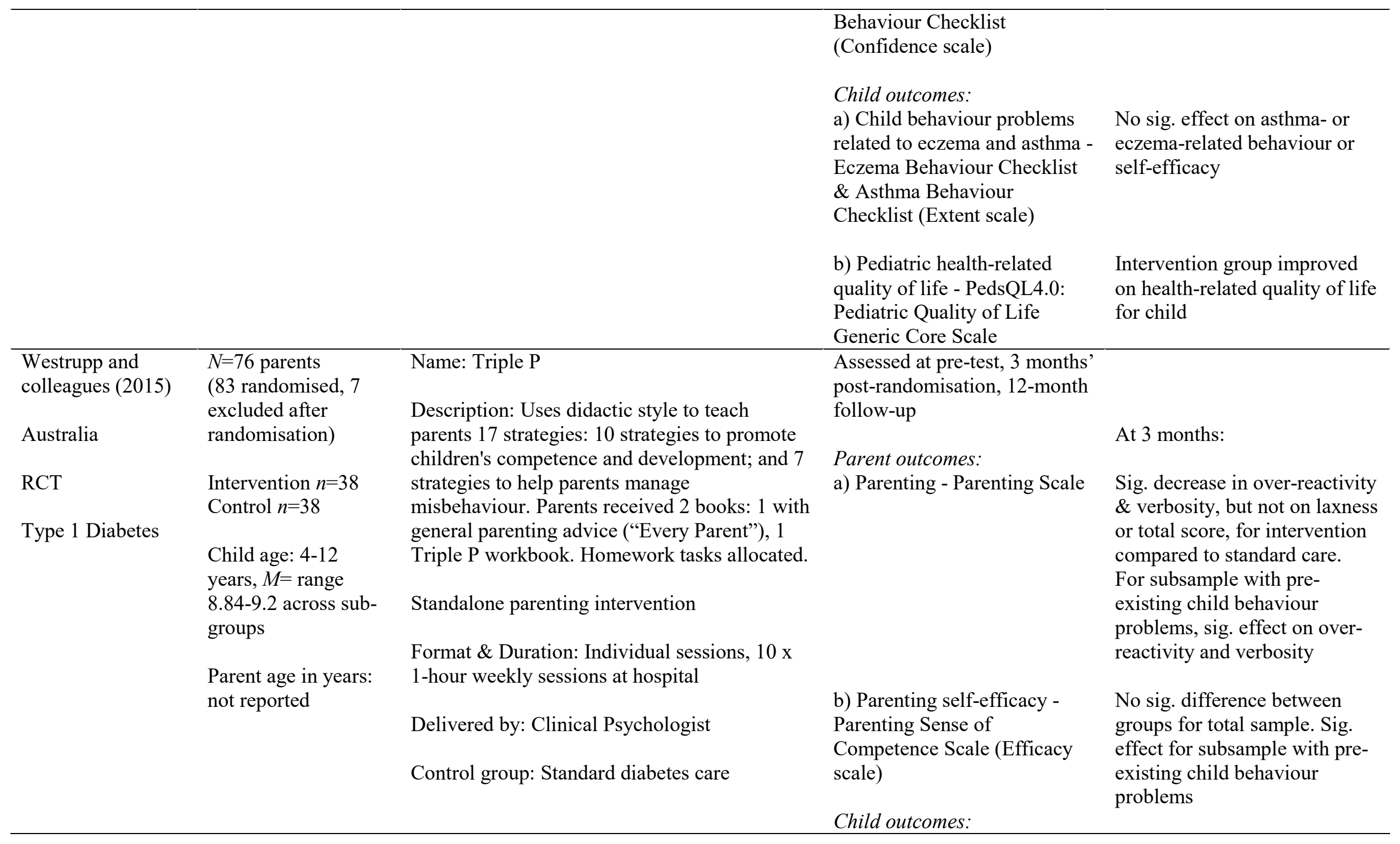


a) Child Behaviour - Parent

Rating Scale of the BASC-2
No sig. difference between

intervention and standard care.

For subsample with pre-

existing child behaviour

problems, sig. improvement

for externalising \&

internalising problems,

intensity \& number of

disruptive behaviours for intervention group compared

to standard care.

b) Glycemic control - HbAlc

levels

c) Disruptive child behaviour -

Eyberg Child Behaviour

Inventory

12-month follow-up for all outcome measures

No difference between intervention and standard care

No sig. difference between groups. For subsample with pre-existing child behaviour problems, sig. improvement in intensity \& number of disruptive behaviours for intervention group compared to standard care.

No sig. intervention effects at 12 months except for total parenting competency for subsample with pre-existing child behaviour problems

\section{Saßmann and} colleagues (2012) $N=65$ mothers and fathers from 33

families (37 families Germany enrolled, 4 withdrew)

Intervention $n=37$
Name: The DELFIN Program

Description: Based on behavioural principles to trengthen general and diabetes specific education competencies.
Assessed at pre-test, post-test

(3 months); 12-month follow-

up for intervention only

Parent outcomes:

a) Parenting behaviour - The 







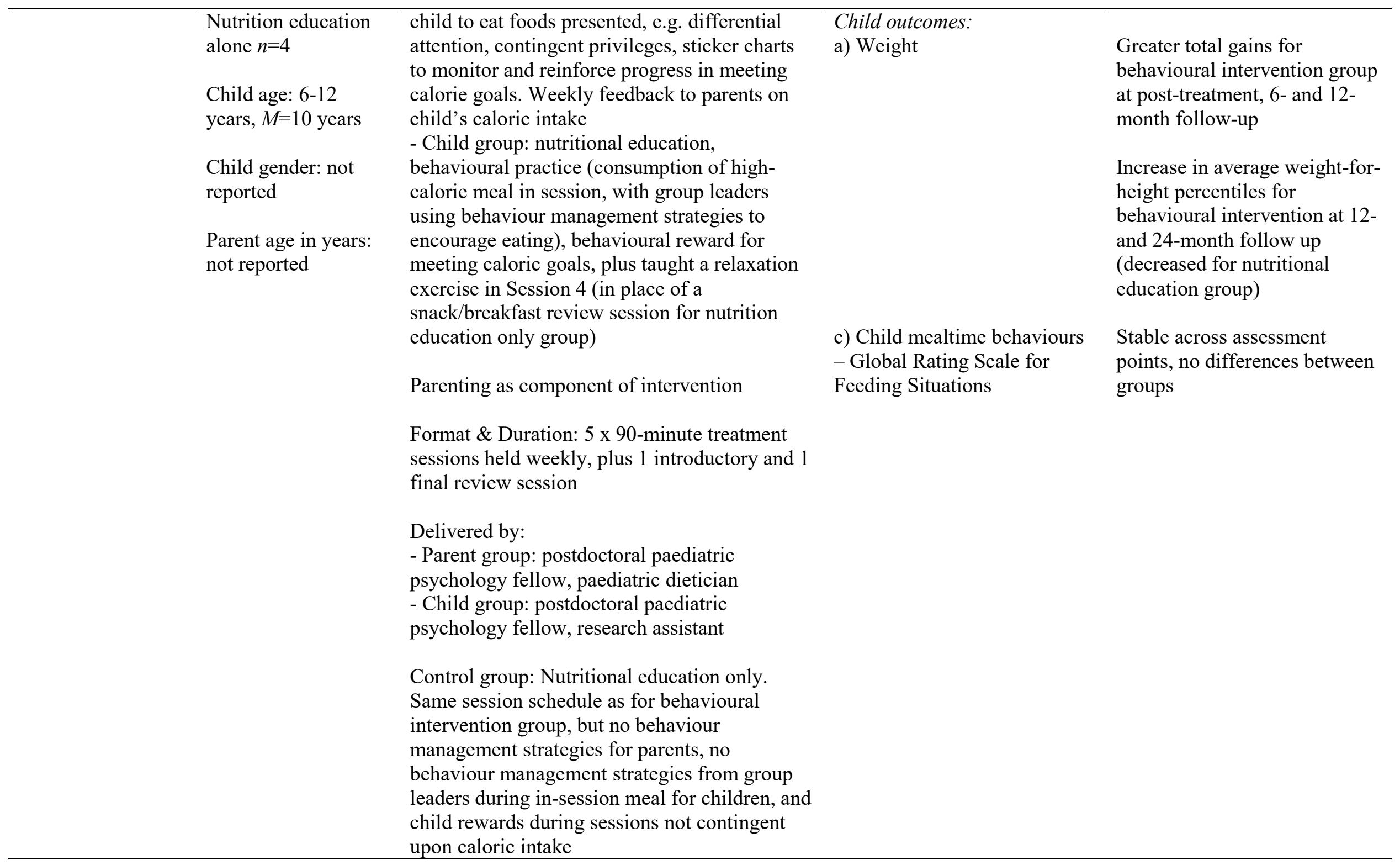




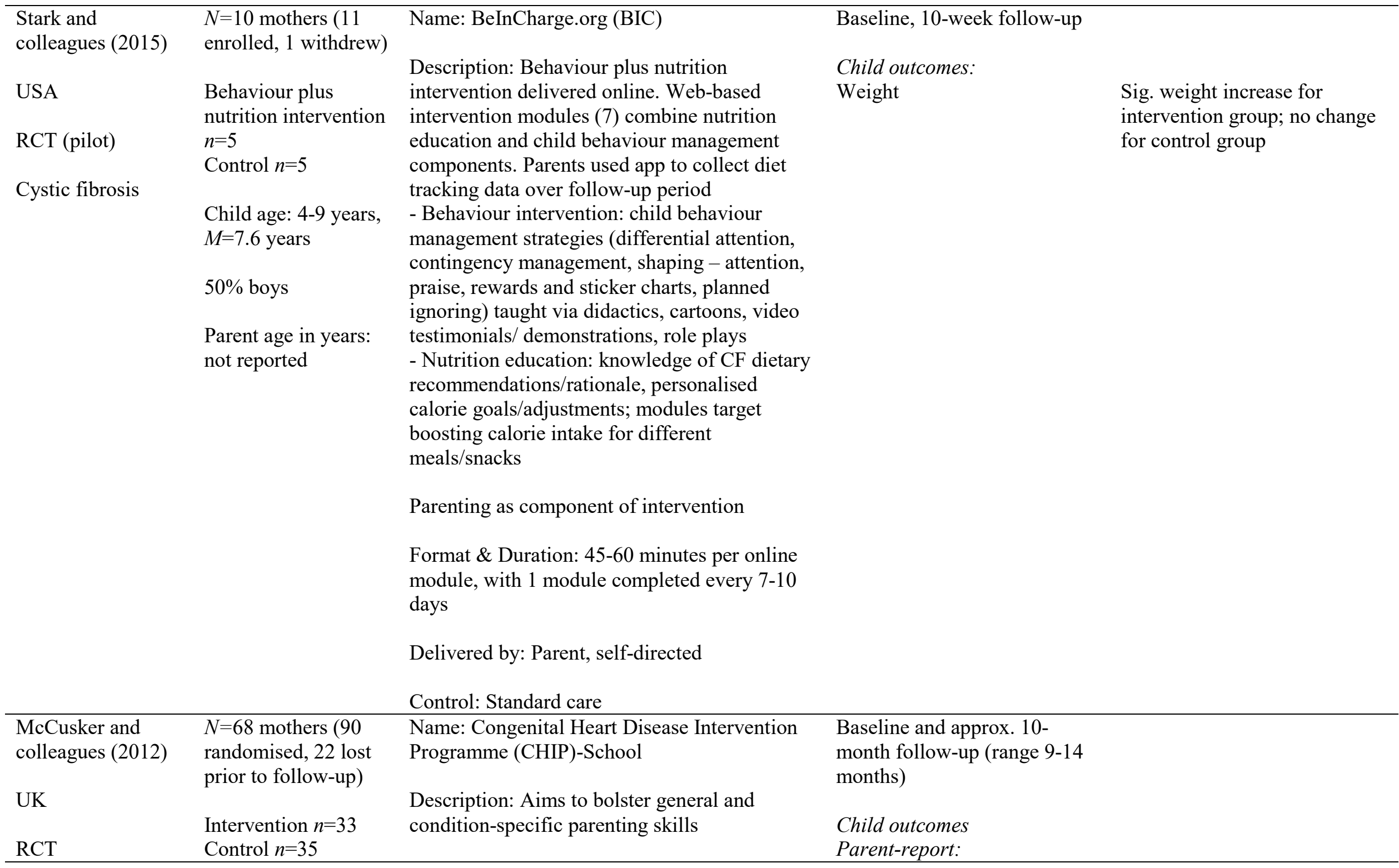




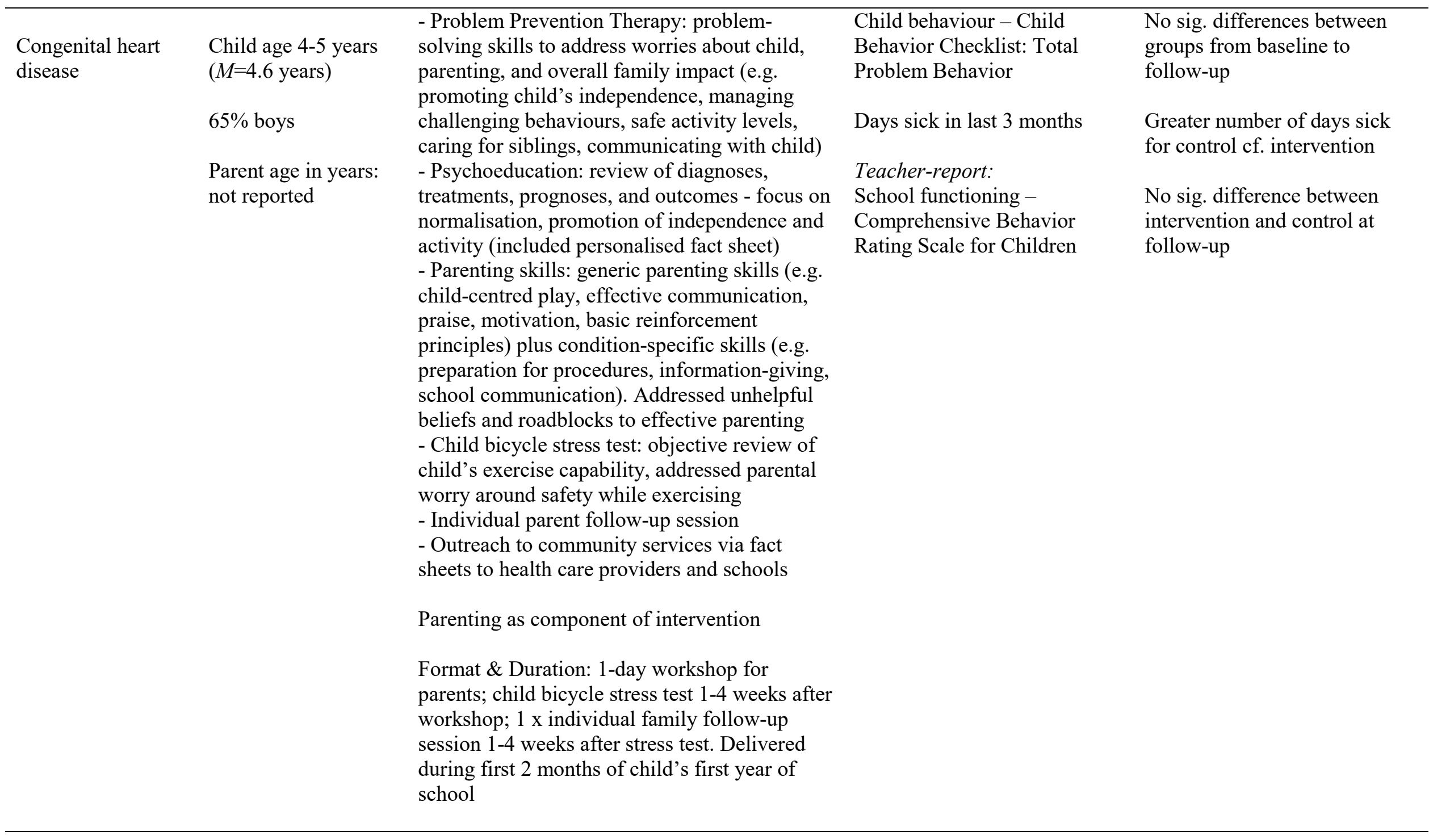


Delivered by: Paediatric clinical psychologists,

paediatric cardiologists, paediatric cardiology

nurse specialist

Note. HbA1c: glycosylated haemoglobin.

Control group: Treatment as usual 
Table 3. Risk of bias assessment of included studies

\begin{tabular}{|c|c|c|c|c|c|c|c|}
\hline $\begin{array}{l}\text { Authors \& } \\
\text { Year }\end{array}$ & $\begin{array}{l}\text { Random sequence } \\
\text { generation }\end{array}$ & $\begin{array}{l}\text { Allocation } \\
\text { concealment }\end{array}$ & $\begin{array}{l}\text { Blinding of } \\
\text { participants } \\
\text { and personnel }\end{array}$ & $\begin{array}{l}\text { Blinding of } \\
\text { outcome } \\
\text { assessments }\end{array}$ & Incomplete outcome data & $\begin{array}{l}\text { Selective } \\
\text { reporting }\end{array}$ & $\begin{array}{l}\text { Other sources of } \\
\text { bias }\end{array}$ \\
\hline $\begin{array}{l}\text { Clarke et al. } \\
(2014)\end{array}$ & $\begin{array}{l}\text { Electronic } \\
\text { randomisation, no } \\
\text { further detail }\end{array}$ & No information & $\begin{array}{l}\text { Blinding not } \\
\text { possible }\end{array}$ & $\begin{array}{l}\text { No } \\
\text { information }\end{array}$ & $\begin{array}{l}\text { No participant completed } \\
\text { intervention, only } 1 \text { completed } \\
\text { post assessment }\end{array}$ & $\begin{array}{l}\text { No } \\
\text { outcomes } \\
\text { reported (no } \\
\text { data) }\end{array}$ & $\begin{array}{l}\text { Small sample size } \\
(N=13)\end{array}$ \\
\hline $\begin{array}{l}\text { Perez et al. } \\
(1999)\end{array}$ & $\begin{array}{l}\text { Method of } \\
\text { randomisation not } \\
\text { mentioned }\end{array}$ & No information & $\begin{array}{l}\text { Blinding not } \\
\text { possible }\end{array}$ & $\begin{array}{l}\text { No } \\
\text { information }\end{array}$ & $\begin{array}{l}\text { Reported attrition from pre- to } \\
\text { post-intervention ( } 33 \%) \text {, reasons } \\
\text { not mentioned, and no } \\
\text { information about attrition by } \\
\text { group. Disease severity higher } \\
\text { for intervention families lost to } \\
\text { follow-up compared to } \\
\text { completers. Only analysed final } \\
\text { data set }\end{array}$ & $\begin{array}{l}\text { All relevant } \\
\text { outcomes } \\
\text { reported }\end{array}$ & $\begin{array}{l}\text { Small sample size } \\
(N=29), \text { little } \\
\text { demographic } \\
\text { information, mean } \\
\text { child age was not } \\
\text { reported }\end{array}$ \\
\hline $\begin{array}{l}\text { Morawska et } \\
\text { al. (2016; } \\
2017 \mathrm{a} \text {; } \\
2017 \mathrm{~b})\end{array}$ & $\begin{array}{l}\text { Block randomisation: } \\
\text { computer-generated } \\
\text { randomly-selected } \\
\text { block sizes, random } \\
\text { group allocation } \\
\text { within each block }\end{array}$ & $\begin{array}{l}\text { External researcher } \\
\text { generated random } \\
\text { allocation sequence, } \\
\text { prepared opaque } \\
\text { envelopes }\end{array}$ & $\begin{array}{l}\text { Blinding not } \\
\text { possible }\end{array}$ & $\begin{array}{l}\text { For } \\
\text { behavioural } \\
\text { coding (video } \\
\text { data) coders } \\
\text { blind to } \\
\text { condition }\end{array}$ & $\begin{array}{l}\text { Included all participants in } \\
\text { analyses, reported attrition by } \\
\text { group and provided reasons, no } \\
\text { significant difference in attrition } \\
\text { by group, similar reasons }\end{array}$ & $\begin{array}{l}\text { All relevant } \\
\text { outcomes } \\
\text { reported }\end{array}$ & $\begin{array}{l}\text { No other bias } \\
\text { identified }\end{array}$ \\
\hline $\begin{array}{l}\text { Westrupp et } \\
\text { al. }(2015)\end{array}$ & $\begin{array}{l}\text { Sequential } \\
\text { randomisation using } \\
\text { pre-prepared cards }\end{array}$ & $\begin{array}{l}\text { Stored in opaque } \\
\text { envelopes } \\
\text { generated by an } \\
\text { independent } \\
\text { statistician }\end{array}$ & $\begin{array}{l}\text { Blinding not } \\
\text { possible }\end{array}$ & $\begin{array}{l}\text { No } \\
\text { information }\end{array}$ & $\begin{array}{l}\text { Intention-to-treat only for } \\
\text { completed responses, reported } \\
\text { attrition per group and overall } \\
\text { reasons, but not whether sig. } \\
\text { difference or reason by group. } \\
\text { Parents lost to follow-up } \\
\text { differed at pre-assessment } \\
\text { compared to completers }\end{array}$ & $\begin{array}{l}\text { All relevant } \\
\text { outcomes } \\
\text { reported }\end{array}$ & $\begin{array}{l}\text { No other bias } \\
\text { identified }\end{array}$ \\
\hline $\begin{array}{l}\text { Saßmann et } \\
\text { al. }(2012\end{array}$ & $\begin{array}{l}\text { Simple randomisation } \\
\text { with a 1:1 allocation } \\
\text { ratio }\end{array}$ & No information & $\begin{array}{l}\text { Blinding not } \\
\text { possible }\end{array}$ & $\begin{array}{l}\text { No } \\
\text { information }\end{array}$ & $\begin{array}{l}\text { Reported attrition by group and } \\
\text { overall reason, similar drop out } \\
\text { per group }\end{array}$ & $\begin{array}{l}\text { All relevant } \\
\text { outcomes } \\
\text { reported }\end{array}$ & $\begin{array}{l}\text { Relatively small } \\
\text { sample size }(N=37) \\
\text { follow-up assessment } \\
\text { for intervention } \\
\text { group only }\end{array}$ \\
\hline
\end{tabular}




\begin{tabular}{|c|c|c|c|c|c|c|c|}
\hline $\begin{array}{l}\text { Stark et al. } \\
(2003)\end{array}$ & $\begin{array}{l}\text { Allocated to am } / \mathrm{pm} \\
\text { timeslot by family } \\
\text { availability; am } / \mathrm{pm} \\
\text { timeslots randomised } \\
\text { by coin flip }\end{array}$ & No information & $\begin{array}{l}\text { Blinding not } \\
\text { possible }\end{array}$ & $\begin{array}{l}\text { For } \\
\text { behavioural } \\
\text { coding (video } \\
\text { data) coders } \\
\text { blind to } \\
\text { condition } \\
\end{array}$ & $\begin{array}{l}\text { Reported overall attrition from } \\
\text { pre- to post-intervention ( } 53 \%) \\
\text { and provided reasons, but no } \\
\text { information about attrition by } \\
\text { group. Only analysed final data } \\
\text { set. }\end{array}$ & $\begin{array}{l}\text { All relevant } \\
\text { outcomes } \\
\text { reported }\end{array}$ & $\begin{array}{l}\text { Very small sample } \\
\text { size }(N=7) \text {; reported } \\
\text { differences between } \\
\text { groups/over time but } \\
\text { no statistical tests of } \\
\text { significance/effect }\end{array}$ \\
\hline $\begin{array}{l}\text { Stark et al. } \\
(2015)\end{array}$ & $\begin{array}{l}\text { Method of } \\
\text { randomisation not } \\
\text { mentioned }\end{array}$ & $\begin{array}{l}\text { Group allocation } \\
\text { via pre-prepared, } \\
\text { sealed envelopes }\end{array}$ & $\begin{array}{l}\text { Blinding not } \\
\text { possible }\end{array}$ & $\begin{array}{l}\text { Assessors for } \\
\text { weight and } \\
\text { caloric intake } \\
\text { blind to } \\
\text { condition }\end{array}$ & $\begin{array}{l}\text { Reported minimal attrition ( } 9 \% \text {; } \\
1 \text { family) with reason, although } \\
\text { no information about attrition } \\
\text { by group }\end{array}$ & $\begin{array}{l}\text { All relevant } \\
\text { outcomes } \\
\text { reported }\end{array}$ & $\begin{array}{l}\text { Very small sample } \\
\text { size }(N=10)\end{array}$ \\
\hline $\begin{array}{l}\text { McCusker et } \\
\text { al. (2012) }\end{array}$ & $\begin{array}{l}\text { Simple randomisation } \\
\text { (chit method) with a } \\
1: 1 \text { allocation ratio }\end{array}$ & No information & $\begin{array}{l}\text { Blinding not } \\
\text { possible }\end{array}$ & $\begin{array}{l}\text { No } \\
\text { information }\end{array}$ & $\begin{array}{l}\text { Reported overall attrition from } \\
\text { pre-intervention to follow-up } \\
\text { ( } 24 \% \text { ) with reasons. Similar } \\
\text { attrition per group. Parents lost } \\
\text { to follow-up differed at pre- } \\
\text { assessment compared to } \\
\text { completers. Father data not } \\
\text { analysed due to insufficient } \\
\text { responses at follow-up }\end{array}$ & $\begin{array}{l}\text { All relevant } \\
\text { outcomes } \\
\text { reported }\end{array}$ & $\begin{array}{l}\text { No other bias } \\
\text { identified }\end{array}$ \\
\hline
\end{tabular}

high risk of bias

unclear risk of bias

low risk of bias 
Table 4. Summary of findings from $N=7$ studies assessed according to GRADE criteria

\begin{tabular}{|c|c|c|c|c|c|}
\hline \multirow[t]{2}{*}{ Outcomes } & \multirow[t]{2}{*}{ Effects } & \multicolumn{2}{|c|}{ No. of participants (studies) } & \multirow{2}{*}{$\begin{array}{l}\text { Quality of the } \\
\text { evidence } \\
\text { (GRADE) }\end{array}$} & \multirow[t]{2}{*}{ Notes } \\
\hline & & Intervention & Comparison & & \\
\hline Parent self-efficacy & $\begin{array}{l}\text { All studies reported greater improvements for } \\
\text { intervention group from pre- to post- } \\
\text { intervention, but only for some condition- } \\
\text { specific measures or subsamples }\end{array}$ & 90 (2 studies) & 93 & $\oplus \bigoplus \ominus \ominus^{\mathrm{a}, \mathrm{b}}$ & $\begin{array}{l}\text { Improved parenting self-efficacy for high- } \\
\text { risk diabetes subsample but not full sample, } \\
\text { not sustained to follow-up ( } 1 \text { study) } \\
\text { Improved self-efficacy with eczema/eczema } \\
\text { behaviour mgt, but not for asthma/asthma } \\
\text { behaviour mgt ( } 1 \text { study) }\end{array}$ \\
\hline $\begin{array}{l}\text { Parenting behaviour } \\
\text { (parent-report) }\end{array}$ & $\begin{array}{l}\text { All studies reported greater improvements for } \\
\text { intervention group from pre- to post- } \\
\text { intervention on some but not all } \\
\text { scales/subscales }\end{array}$ & 127 (3 studies) & 117 & $\bigoplus \bigoplus \ominus \ominus^{\mathrm{a}, \mathrm{b}}$ & $\begin{array}{l}\text { Improvements in some ineffective parenting } \\
\text { (laxness/overreactivity/verbosity) subscales } \\
\text { ( } 3 \text { of } 3 \text { studies); no change in helping/ } \\
\text { reinforcing parenting behaviours ( } 1 \text { study) }\end{array}$ \\
\hline $\begin{array}{l}\text { Parenting behaviour } \\
\text { (observed) }\end{array}$ & All studies reported no change & 55 (2 studies) & 59 & $\bigoplus \bigoplus \ominus \ominus^{\mathrm{a}, \mathrm{c}}$ & \\
\hline $\begin{array}{l}\text { Illness severity or } \\
\text { control }\end{array}$ & $\begin{array}{l}5 \text { studies reported improvements in illness } \\
\text { severity/control from pre- to post-intervention; } \\
2 \text { studies reported no change }\end{array}$ & 167 (7 studies) & 163 & $\bigoplus \bigoplus \ominus \ominus^{\mathbf{a}, \mathbf{c}}$ & $\begin{array}{l}\text { Improvements for asthma, eczema, cystic } \\
\text { fibrosis, congenital heart disease ( } 5 \text { studies) } \\
\text { No change for type } 1 \text { diabetes ( } 2 \text { studies })\end{array}$ \\
\hline Child HRQoL & $\begin{array}{l}1 \text { study reported improvement from pre- to } \\
\text { post-intervention and follow-up }\end{array}$ & 52 (1 study) & 55 & $\oplus \oplus \oplus \ominus^{\mathrm{a}}$ & $\begin{array}{l}\text { Intervention effect for father-report only } \\
\text { (equal improvement for intervention and } \\
\text { control groups for mother-report) }\end{array}$ \\
\hline $\begin{array}{l}\text { Child behaviour } \\
\text { (parent report) }\end{array}$ & $\begin{array}{l}3 \text { studies reported improvements for some but } \\
\text { not all measures of child behaviour, or for } \\
\text { subsample only; } 2 \text { studies reported no change }\end{array}$ & 177 (5 studies) & 164 & $\bigoplus \ominus \ominus \ominus^{\mathrm{a}, \mathrm{b}, \mathrm{c}}$ & $\begin{array}{l}\text { Improved general behaviour for full sample } \\
\text { or subsample ( } 3 \text { of } 4 \text { studies) } \\
\text { Improved asthma behaviour problems ( } 1 \text { of } 2 \\
\text { studies), eczema behaviour problems for } \\
\text { mother-report but not father-report ( } 1 \text { study) }\end{array}$ \\
\hline $\begin{array}{l}\text { Child behaviour } \\
\text { (observed) }\end{array}$ & All studies reported no change & 55 (2 studies) & 59 & $\bigoplus \oplus \ominus \ominus^{\mathrm{a}, \mathrm{c}}$ & \\
\hline
\end{tabular}

(observed)

Note. GRADE: Grading of Recommendations Assessment, Development, and Evaluation.

GRADE Working Group grades of evidence: High quality $\oplus \oplus \oplus \oplus$ : Very confident that the true effect lies close to that of the estimate of the effect. Moderate quality

$\oplus \oplus \oplus \ominus$ : The true effect is likely to be close to the estimate of the effect, but there is a possibility that it is substantially different. Low quality $\oplus \oplus \ominus \ominus$ : The true effect may be substantially different from the estimate of the effect. Very low quality $\oplus \ominus \ominus \ominus$ : The true effect is likely to be substantially different from the estimate of effect. 
${ }^{\mathrm{a}}$ Imprecision of results due to small sample sizes

${ }^{b}$ Inconsistency (heterogeneity in study results)

${ }^{\mathrm{c}}$ Limitations due to study design and implementation and associated risks of bias 